analysis of zygapophyseal joints in patients with ankylosing spondylitis. Arthritis Rheum 2006:54:2845-51.

17. Rudwaleit M, Schwarzlose S, Hilgert ES, Listing J, Braun J, Sieper J. MRI in predicting a major clinical response to anti-tumour necrosis factor treatment in ankylosing spondylitis. Ann Rheum Dis 2008;67:1276-81.

18. Bennett AN, Rehman A, Hensor EMA, Marzo-Ortega $\mathrm{H}$, Emery $\mathrm{P}, \mathrm{Mc}$ Gonagle D. Evaluation of the diagnostic utility of spinal MRI in axial spondyloarthritis. Arthritis Rheum 2009. In press.
19. Puhakka KB, Jurik AG, Schiottz-Christensen B, Hansen GV, Egund N, Christiansen JV, et al. MRI abnormalities of sacroiliac joints in early spondylarthropathy:a 1-year follow-up study. Scand J Rheumatol 2004;33:332-8

\title{
New tumour necrosis factor inhibitors for rheumatoid arthritis: are there benefits from extending choice?
}

\section{David L Scott, ${ }^{1}$ Andrew Cope ${ }^{2}$}

Certolizumab pegol (UCB, Brussels, Belgium) and golimumab (Centocor, Horsham, Pennsylvania, USA) are the latest tumour necrosis factor (TNF) inhibitors evaluated in double-blind, multicentre randomised controlled trials (RCT). Certolizimab is the pegylated (polyethylene glycolated) $\mathrm{Fab}^{\prime}$ fragment derived from a high affinity humanised antiTNF $\alpha$ monocolonal antibody (mAb). Fab' fragments lack the Fc portion of immunoglobulin, and so the repertoire of Fcmediated effector responses, such as complement or antibody-dependent cellmediated cytotoxicity, is distinct from those of other anti-TNF mAb. Nonetheless, it still neutralises membrane TNF $\alpha$. Derivatisation of the Fab' fragment prolongs the plasma half-life to 2 weeks. Certolizumab pegol is administered by subcutaneous injection (200 or $400 \mathrm{mg}$ ) every 2 weeks. Golimumab is a human anti-TNF $\mathrm{mAb}$ administered by subcutaneous injections (50 or $100 \mathrm{mg}$ ) every 4 weeks. Three RCT in this issue of Annals of the Rheumatic Diseases, ${ }^{1-3}$ (see pages 789, 797 and 805) which report their use in active rheumatoid arthritis (RA), raise two questions. First, do we need more TNF inhibitors? Second, how effective and safe are these new TNF inhibitors?

Successful drugs are invariably replicated. "Breakthrough" treatments sound more impressive than subsequent "me

\footnotetext{
${ }^{1}$ Academic Department of Rheumatology, King's College London School of Medicine, Weston Education Centre, King's College London, London, UK; ${ }^{2}$ Academic Department of Rheumatology, King's College London School of Medicine, Guy's Hospital, London, UK

Correspondence to: Professor D L Scott, Academic Department of Rheumatology, King's College London School of Medicine, Weston Education Centre, King's College London, 10 Cutcombe Road, London SE5 9RS, UK; david.I.scott@kcl.ac.uk
}

too" replications, although the latter products might perform better. $\mathrm{Lee}^{4}$ has elegantly summarised the arguments for "me too" products, indicating that their presence "does not mean that imitation has replaced innovation". Successful "me too" treatments improve efficacy, reduce toxicity and increase "cost effectiveness". With biological agents such as TNF inhibitors their added benefits may include more favourable routes or frequencies of administration.

There are cogent reasons to anticipate that "me too" biological agents will be commonplace as experience with these agents solidifies and their use increases. There may be special factors with biologicals, particularly around their mechanism of action, which may complicate the comparison of different "me too" products. Nevertheless, it is generally appropriate to assume that what holds for conventional drugs also holds for large molecules with regard to the benefits of "me too" products. Indeed, regulatory developments have paved the way for future biosimilars or follow-on biologicals to be developed as the patent life of established molecules draws to a close..$^{5}$

There are many critics of "me too" conventional drugs. ${ }^{6}$ Clinicians often use only one or two drugs in each class and may not need wide choices. Furthermore, much expenditure on drugs is attributable to high-cost "me too" products. However, this issue is complex because it could represent either high expenditure on unneeded replication or a realistic preference for refined "me too" products over less effective or more toxic "breakthrough" products. Overall, the proliferation of agents in a successful treatment class reflects the competitive nature of drug development, the length of the regulatory process and the risks of first agents in a class not achieving registration. It seems unlikely that "me too" products stifle the development of novel agents; recent history suggests "me too" agents are an inevitable part of the process of finding new products.

Two RCT reported in this issue evaluated the new TNF inhibitors combined with methotrexate in disease-modifying antirheumatic drug (DMARD) non-responders. American College of Rheumatology $50 \%$ improvement (ACR50) responder rates at 6 months can be used to place the results in context. With golimumab-methotrexate ACR50 responder rates were 35\% compared with $14 \%$ with controls; ${ }^{2}$ in a previous dose-ranging trial ACR50 responder rates were $31 \%$ with active treatment and $6 \%$ in controls. ${ }^{8}$ Certolizumab pegol/ methotrexate gave ACR50 responder rates of $33 \%$ compared with $3 \%$ with controls; ${ }^{1}$ in a previous phase III trial ACR50 responder rates were $37-40 \%$ compared with $8 \%$ with controls. ${ }^{9}$ We extended this analysis of ACR50 responder rates at 6 months across TNF inhibitor-methotrexate combinations, using key RCT in established RA identified in a previous systematic review. ${ }^{10-13}$ Although this analytical approach has its limitations as the trials were undertaken at different times and in different populations, it is possible to gain some understanding of the overall efficacy of different TNF inhibitors from this type of comparative analysis. The number needed to treat (NNT) to achieve an ACR50 response compared with methotrexate monotherapy ranges from 3 to 5 (table 1). These results show that both established and new TNF inhibitors have similar efficacy when combined with methotrexate.

Established TNF inhibitors prevent erosive progression over 12 months and beyond. Comparative 6-month data for certolizumab pegol suggest it reduces erosive damage and its efficacy is similar to etanercept and adalimumab ${ }^{12}{ }^{13}$ (fig 1). Whereas conventional assessments of erosive damage use 12-month changes, 6 month changes are equally impressive with all these agents. Although comparable 6-month data on erosive progression are not available for infliximab and golimumab, their absence is most likely 
Table 1 Six-month ACR50 responders in key RCT comparing methotrexate with methotrexate/TNF inhibitor combinations

\begin{tabular}{|c|c|c|c|c|c|c|}
\hline Biological agent & Trial & Group & Recruited & $\begin{array}{l}\text { ACR50 } \\
\text { responders }\end{array}$ & $\begin{array}{l}\text { Percentage of } \\
\text { responders (\%) }\end{array}$ & NNT \\
\hline \multirow[t]{2}{*}{ Infliximab } & \multirow[t]{2}{*}{ Maini et al (1999) ${ }^{11}$} & $3 \mathrm{mg} / \mathrm{kg}$ per 8 weeks & 86 & 22 & 27 & $5(4-9)$ \\
\hline & & $3 \mathrm{mg} / \mathrm{kg}$ per 4 weeks & 86 & 25 & 29 & $4(3-7)$ \\
\hline \multirow[t]{2}{*}{ Etanercept } & \multirow[t]{2}{*}{ Klareskog et al $(2004)^{12}$} & $2 \times 25 \mathrm{mg} /$ week & 231 & 136 & 59 & $3(3-4)$ \\
\hline & & Placebo & 228 & 93 & 41 & - \\
\hline Adalimumab & Keystone et al (2004) ${ }^{13}$ & $40 \mathrm{mg} / 2$ weeks & 207 & 81 & 39 & $3(3-5)$ \\
\hline \multirow{2}{*}{ Golimumab } & \multirow{2}{*}{ Keystone et al (2009) } & $100 \mathrm{mg} / 4$ weeks & 89 & 29 & 33 & $5(3-13)$ \\
\hline & & Placebo & 133 & 18 & 14 & - \\
\hline \multirow[t]{4}{*}{ Certolizumab pegol } & \multirow[t]{3}{*}{ Smolen et al (2009) } & $200 \mathrm{mg} / 4$ weeks & 246 & 80 & 33 & $3(3-4)$ \\
\hline & & $400 \mathrm{mg} / 4$ weeks & 246 & 81 & 33 & $3(3-4)$ \\
\hline & & Placebo & 127 & 4 & 3 & - \\
\hline & Keystone et al (2009) & $200 \mathrm{mg} / 4$ weeks & 393 & 146 & 37 & $3(3-4)$ \\
\hline
\end{tabular}

These trials differed in the type of patients enrolled, their initial disease activities and the clinical situation from which they were drawn (treatment in the 1990 s was different to the 2005-8 era). These differences explain variations in the absolute numbers of active and placebo responders. However, the relationship between active and placebo treatments shown by the number needed to treat (NNT) should not be affected by these variations. ACR50, American College of Rheumatology $50 \%$ improvement; RCT, randomised controlled trial; TNF, tumour necrosis factor.

reflecting study design than relative efficacy.

The efficacy of TNF inhibitor monotherapy was investigated in the RCT comparing certolizumab pegol with placebo therapy in 222 DMARD failure patients. $^{3}$ Six-month ACR50 responder rates were $24 \%$ with certolizumab pegol compared with $4 \%$ for placebo. This is comparable to the efficacy of etanercept monotherapy in the Tempo study. ${ }^{12}$ Some patients use TNF inhibitor monotherapies, as a result of personal choice or toxicity with methotrexate and other DMARD. In these patients TNF inhibitor monotherapies can be used and are likely to be effective, but less so than combination therapy. To date, this appears to be true for all members of the class, a finding supported by the data of Fleischmann et $a l^{3}$ that showed comparable rates of neutralising antibodies to certolizumab

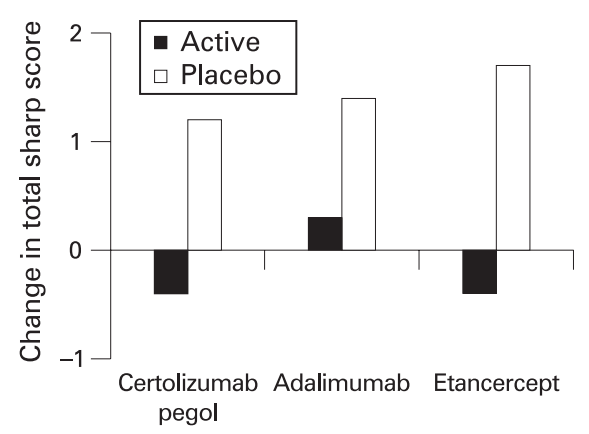

Figure 1 Radiological progression over 6 months in key randomised controlled trials ${ }^{112}{ }^{13}$ comparing methotrexate with methotrexate/tumour necrosis factor inhibitor combinations. pegol (8\%) to those with neutralising antibodies to the other TNF inhibitors.

As a consequence of reducing synovitis and erosive damage, TNF inhibitors also improve disability and quality of life. There is strong evidence that the existing TNF inhibitors-infliximab, etanercept and adalimumab-all achieve these goals. ${ }^{14} 15$ RCT show that golimumab and certolizumab pegol also reduce health assessment questionnaire scores. Further data are certain to show these biological agents also have positive effects on quality of life.

Adverse effects are more complex. The trial data in the present and other reports all suggest TNF inhibitors are relatively safe agents. The major concern with them-their "Achilles heel" in terms of being ideal treatments-is their propensity to increase the risk of infections. ${ }^{16}{ }^{17}$ The level of risk of severe infections appears relatively small but RCT are insufficiently large to define the level of risk accurately. One issue that these and other recent studies do appear to highlight, is the fact that there is unlikely to be any major benefit to using Fc-free TNF inhibitors over $\mathrm{mAb}$ in populations in which latent tuberculous infection is endemic. Treatment registries, mainly from Europe, have provided invaluable "real life" data on adverse events in general, and infectious risks in particular. ${ }^{18-20}$ They demonstrate that the risks are small, although not insubstantial. The data on existing TNF inhibitors are substantial and the conclusions are robust. There will be little comparable information with new TNF inhibitors and this could be seen to place them at a disadvantage.

Competition should drive up efficiency and drive down prices of TNF inhibitors. This could result from decreasing costs, improving efficacy or a combination of the two. Patients should benefit from the competition created by extending the number of TNF inhibitors available. Ultimately, health economics will determine the use of TNF inhibitors. There are national variations in the current use of these biological agents that span differences in both guidance and use, ${ }^{21-23}$ which most likely reflects different approaches to assessing the value of high-cost treatments. It will be interesting to see if the introduction of newer TNF inhibitors will change either guidance or use. From the perspective of UK guidance, increasing cost-effectiveness should change guidance and extend the use of biological treatments. The introduction of two new TNF inhibitors is also likely to increase the overall use of these agents and to encourage switching between agents, even though this remains an area of controversy. ${ }^{24} 25$

A key question is how to select the first TNF inhibitor to give patients. One factor is patient preference. Both the route and frequency of administration influence patients' views and not all patients want or need an identical approach. A key factor is the relative efficacy of the different biologicals. In the absence of head-to-head trials caution is needed when comparing results from different placebo-controlled trials of these TNF inhibitors. Overall, there are only minor 
differences in NNT, which are unlikely to be clinically relevant. A third factor is toxicity. To date there is only marginal evidence for different toxicities, and trials in particular are not the ideal way to collect information about toxicity; large observational cohorts, particularly registries, are more useful. Different mechanisms of action might provide a theoretical rationale to prefer one agent over another. Now that Fc-free inhibitors have been evaluated in large trials we can conclude that Fc effector function is not essential for efficacy and true cytokine inhibition lies behind the biological effects of therapy. So far there is no reason to prefer one particular TNF inhibitor due to its mode of action. The overriding pressure to choose one particular TNF inhibitor is likely to be economic. The most costeffective TNF inhibitor is likely to be the most sensible choice. In this context differences in both the overall cost of administration and in the health gains from treatment-even relatively minor differences-will be of key importance. For the present there are no data on the cost-effectiveness of the newer TNF inhibitors and so it is not possible to make an informed choice. This is an area in which further research is urgently needed; ideally this should be undertaken independently of the manufacturer and regulatory bodies. In summary, the data so far suggest that the five biological agents are very similar and there is no clear reason to prefer one over another.

There are several outstanding issues. As many patients with active RA are nonresponders to TNF inhibitors, there is a pressing need to develop biomarkers that distinguish responders from non-responders at the outset of treatment. Directed biological therapy should be a realistic short to medium-term goal. Such an approach exemplifies the need to optimise outcomes, minimise toxicity and deliver cost-effective care when using TNF inhibitors. Turning this ethos into a reality means we need to acquire the molecular toolkit to redefine RA as a heterogeneous spectrum of syndromes driven by distinct inflammatory pathways.
Competing interests: None.

Accepted 10 March 2009

Ann Rheum Dis 2009;68:767-769.

doi:10.1136/ard.2008.105940

\section{REFERENCES}

1. Smolen JS, Landewé RB, Mease PJ, Brzezicki J, Mason D, Luijtens K, et al. Efficacy and safety of certolizumab pegol plus methotrexate in active rheumatoid arthritis: the RAPID 2 Study. Ann Rheum Dis 2009;68:789-96.

2. Keystone EC, Genovese MC, Klareskog L, Hsia EC, Hall ST, Miranda PC, et al. Golimumab, a human antibody to TNF-\{alpha\} given by monthly subcutaneous injections, in active rheumatoid arthritis despite methotrexate: the GO-FORWARD Study. Ann Rheum Dis 2009;68:805-11.

3. Fleischmann $\mathbf{R}$, Vencovsky J, van Vollenhoven $R$, Borenstein D, Box J, Coteur G, et al. Efficacy and safety of certolizumab pegol monotherapy every 4 weeks in patients with rheumatoid arthritis failing previous disease-modifying antirheumatic therapy: the FAST4WARD study. Ann Rheum Dis 2009;68:797-804.

4. Lee TH. "Me-too" products—-friend or foe? N Engl J Med 2004;350:211-12.

5. Wiecek A, Mikhail A. European regulatory guidelines for biosimilars. Nephrol Dial Transplant 2006;21 (Suppl 5):17-20.

6. Morgan SG, Bassett KL, Wright JM, Evans RG, Barer $\mathrm{ML}$, Caetano PA, et al. "Breakthrough" drugs and growth in expenditure on prescription drugs in Canada. BMJ 2005;331:815-16.

7. DiMasi JA, Paquette C. The economics of follow-on drug research and development: trends in entry rates and the timing of development. Pharmacoeconomics 2004;22(2 Suppl 2):1-14.

8. Kay J, Matteson EL, Dasgupta B, Nash P, Durez P, Hall S, et al. Golimumab in patients with active rheumatoid arthritis despite treatment with methotrexate: a randomized, double-blind, placebocontrolled, dose-ranging study. Arthritis Rheum 2008;58:964-75.

9. Keystone E, Heijde D, Mason D Jr, Landewé R, Vollenhoven RV, Combe B, et al. Certolizumab pegol plus methotrexate is significantly more effective than placebo plus methotrexate in active rheumatoid arthritis: findings of a fifty-two-week, phase III, multicenter, randomized, double-blind, placebocontrolled, parallel-group study. Arthritis Rheum 2008:58:3319-29.

10. Kristensen LE, Christensen R, Bliddal H, Geborek P, Danneskiold-Samsøe B, Saxne T. The number needed to treat for adalimumab, etanercept, and infliximab based on ACR50 response in three randomized controlled trials on established rheumatoid arthritis: a systematic literature review. Scand J Rheumatol 2007;36:411-17.

11. Maini R, St Clair EW, Breedveld F, Furst D, Kalden J, Weisman M, et al. Infliximab (chimeric anti-tumour necrosis factor alpha monoclonal antibody) versus placebo in rheumatoid arthritis patients receiving concomitant methotrexate: a randomised phase III trial. ATTRACT Study Group. Lancet 1999;354:1932-9.

12. Klareskog L, van der Heijde D, de Jager JP, Gough A, Kalden J, Malaise M, et al. Therapeutic effect of the combination of etanercept and methotrexate compared with each treatment alone in patients with rheumatoid arthritis: double-blind randomised controlled trial. Lancet 2004;363:675-81.

13. Keystone EC, Kavanaugh AF, Sharp JT, Tannenbaum $\mathrm{H}$, Hua Y, Teoh LS, et al. Radiographic, clinical, and functional outcomes of treatment with adalimumab la human anti-tumor necrosis factor monoclonal antibody) in patients with active rheumatoid arthritis receiving concomitant methotrexate therapy. A randomized, placebo-controlled, 52-week trial. Arthritis Rheum 2004;50:1400-11.

14. Doan QV, Chiou CF, Dubois RW. Review of eight pharmacoeconomic studies of the value of biologic DMARDs (adalimumab, etanercept, and infliximab) in the management of rheumatoid arthritis. J Manag Care Pharm 2006;12:555-69.

15. Chen YF, Jobanputra P, Barton P, Jowett S, Bryan S, Clark W, et al. A systematic review of the effectiveness of adalimumab, etanercept and infliximab for the treatment of rheumatoid arthritis in adults and an economic evaluation of their costeffectiveness. Health Technol Assess 2006;10:1-229.

16. Bongartz T, Sutton AJ, Sweeting MJ, Buchan I, Matteson EL, Montori V. Anti-TNF antibody therapy in rheumatoid arthritis and the risk of serious infections and malignancies: systematic review and metaanalysis of rare harmful effects in randomized controlled trials. JAMA 2006;295:2275-85.

17. Furst DE. The risk of infections with biologic therapies for rheumatoid arthritis. Semin Arthritis Rheum 2009, in press.

18. Zink A, Askling J, Dixon WG, Klareskog L, Silman AJ, Symmons DP. European Biologics Registers methodology, selected results, and perspectives. Ann Rheum Dis 2009, in press.

19. Wolfe F, Michaud K. Biologic treatment of rheumatoid arthritis and the risk of malignancy: analyses from a large US observational study. Arthritis Rheum 2007:56:2886-95.

20. Weaver AL, Lautzenheiser RL, Schiff MH, Gibofsky A, Perruquet JL, Luetkemeyer J, et al. The RADIUS Investigators. Real-world effectiveness of select biologic and DMARD monotherapy and combination therapy in the treatment of rheumatoid arthritis: results from the RADIUS observational registry. Curr Med Res Opin 2006;22:185-98.

21. Kay LJ, Griffiths ID, BSR Biologics Register Management committee. UK consultant rheumatologists' access to biological agents and views on the BSR Biologics Register. Rheumatology 2006;45:1376-9.

22. Saag KG, Teng GG, Patkar NM, Anuntiyo J, Finney C, Curtis JR, et al. American College of Rheumatology 2008 recommendations for the use of nonbiologic and biologic disease-modifying antirheumatic drugs in rheumatoid arthritis. Arthritis Rheum 2008:59:762-84

23. Yazici Y, Shi N, John A. Utilization of biologic agents in rheumatoid arthritis in the United States: analysis of prescribing patterns in 16,752 newly diagnosed patients and patients new to biologic therapy. Bull NY U Hosp Jt Dis 2008;66:77-85.

24. Keystone EC. Switching tumor necrosis factor inhibitors: an opinion. Nat Clin Pract Rheumatol 2006;2:576-7.

25. Erickson AR, Mikuls TR. Switching anti-TNF-alpha agents: what is the evidence? Curr Rheumatol Rep 2007:9:416-20. 